\section{International Scientific Journal Theoretical \& Applied Science}

p-ISSN: 2308-4944 (print) $\quad$ e-ISSN: 2409-0085 (online)

Year: $2017 \quad$ Issue: 09 Volume: 53

Published: 7.09.2017 http://T-Science.org
Elena Viktorovna Bergal candidate of economic Sciences, docent of Kuban State University

Galina Vladimirovna Dmiterko student, Kuban State University, Specialist of the 1st category of the Federal Tax Service of Russia №4 for Krasnodar

SECTION 31. Economic research, finance, innovation, risk management.

\title{
MOBILIZATION OF TAX REVENUES AND MODERN TRENDS OF TAX ADMINISTRATION OF SMALL AND MEDIUM BUSINESS ENTERPRISES
}

\begin{abstract}
The article analyzes the current state of taxation of small businesses and marked the positive and negative trends in the state tax policy this sector of the economy. On the basis of a critical assessment of the current system of tax administration of small businesses, the main problems that lead to the flight of taxpayers into the shadow economy and the main directions development of relations between the state and small and mediumsized businesses.

Key words: the state administration in the field of taxes and fees, small and medium businesses, tax burden, tax system, shadow economy.

Language: Russian

Citation: Bergal EV, Dmiterko GV (2017) MOBILIZATION OF TAX REVENUES AND MODERN TRENDS OF TAX ADMINISTRATION OF SMALL AND MEDIUM BUSINESS ENTERPRISES. ISJ Theoretical \& Applied Science, 09 (53): 18-22.

Soi: http://s-o-i.org/1.1/TAS-09-53-4 Doi: crossef https://dx.doi.org/10.15863/TAS.2017.09.53.4

\section{МОБИЛИЗАЦИЯ НАЛОГОВЫХ ДОХОДОВ И СОВРЕМЕННЫЕ ТЕНДЕНЦИИ НАЛОГОВОГО АДМИНИСТРИРОВАНИЯ ПРЕДПРИЯТИЙ МАЛОГО И СРЕДНЕГО БИЗНЕСА}

Аннотация: В статье проведен анализ современного состояния налогового администрирования субъектов малого и среднего предпринимательства, отмечены позитивные и негативные тенденции государственной налоговой политики данного сектора экономики. На основании результатов критической оценки действующей системы налогового администрирования субъектов малого бизнеса, выявлены основные проблемы, приводящие к бегству налогоплательщиков в теневой бизнес и определены основнье направления развития взаимоотношений государства и субъектов малого и среднего бизнеса.

Ключевые слова: государственное администрирование налогов и сборов, субъекты малого и среднего предпринимательства, налоговое бремя, налоговая система, теневая экономика.
\end{abstract}

\section{Introduction}

На современном этапе развития в период политики финансовых ограничений и санкций стабильность налоговой системы является гарантом финансовой устойчивости государства. Создание эффективной налоговой системы, обеспечивающей бюджетную устойчивость на долгосрочный период, является основным приоритетом России в области налоговой политики. Особая роль здесь отводится совершенствованию инструментов налогового администрирования субъектов малого и среднего бизнеса, что и определяет актуальность данного исследования. Малый и средний бизнес формируют порядка 20,0\% ВВП страны, в связи с чем, вопросы налогообложения указанной категории плательщиков актуальны, так как затрагивают права и интересы налогоплательщиков, общества и государства. Полагаем, что именно малый и средний бизнес призван обеспечить рост ВВП и налоговых доходов бюджетов всех уровней. На начало 2017 года в России зарегистрировано и действует 189,2 тыс субъектов малого бизнеса, без учета микро предприятий, на которых занято более 5,9 млн человек [3]. Именно субъекты малого и среднего предпринимательства призваны решать задачи обеспечения государства необходимыми финансовыми ресурсами, наращивания 
производства товаров и услуг, роста занятости населения и повышения его материального благосостояния.

Вопросы налогового администрирования малого и среднего бизнеса в России, а также проблемы стратегического развития налоговой системы и взаимодействия в процессе администрирования налогов государства и предпринимателей, рассматривали ученыеэкономисты Ефремова Т.А., Ильин А.В., Долгов С.Г, Гоголев А.М. и другие. Однако исследуемая тема в отечественной литературе полностью не изучена.

Цель настоящего исследования - оценка современного состояния налогового администрирования субъектов малого и среднего бизнеса, выявление проблем, приводящих к бегству налогоплательщиков в теневую экономику, а также рассмотрение основных направлений развития и гармонизации взаимоотношений государственных контролирующих органов и субъектов бизнеса.

\section{Materials and Methods}

В ходе проведенного исследования установлено, что при низком уровне собираемости налогов федеральное правительство и субъекты федерации не смогут выполнять все расходные обязательства, возникающие в рамках предметов ведения, и прежде всего социальные. Растущая из года в год в абсолютном выражении налоговая задолженность является серьезной проблемой, поскольку как следствие формируется ограничение объема финансовых ресурсов государства. На сайте ФНС России представлены статистические данные формы 4-НМ по субъектам РФ, анализ которых показывает, что за последние годы имеет место стабильный рост задолженности по уплате налогов и сборов как на уровне РФ, так и в разрезе федеральных округов.

Анализируя годовые отчеты 1-НМ по РФ за последние три года не смотря на незначительный рост поступлений по отдельным налогам на конец 2016 года, катастрофическими темпами растет общая недоимка, налоговая задолженность суммарно увеличилась за три года на $1,4 \%$ и составила17 663093 тыс руб.

В ходе исследования нами выявлены следующие причины, влияющие на собираемость налогов и сборов.

Во-первых, теневая экономика. По данным Росстата более 30,0 \% хозяйствующих субъектов осуществляют торговую деятельность, из них $60,0 \%$ относятся к индивидуальным предпринимателям. Объем теневой экономики России составляет 16,0 \% ВВП [3]. По мнению экспертов всемирного банка, данный показатель существенно выше - более $40,0 \%$ ВВП.
Независимые эксперт определяют размер сектора теневой экономики в критические 52,6\% ВВП [4]. Такие компании либо совсем ничего не платят, либо перечисляют в бюджет меньше, чем должны по закону. Сформировавшийся в экономике высокий уровень уклонения от уплаты налогов способствует переложению налоговой нагрузки на законопослушных налогоплательщиков и в итоге ведет к снижению наполняемости бюджетов всех уровней.

Во-вторых, действующие формы и средства налогообложения экономически не привязаны к реальной хозяйственной жизни, их воздействие на производственные процессы имеет исключительно фискальный характер. В таких условиях даже позитивные сдвиги в экономической действительности не дают оснований надеяться на прирост налоговых поступлений.

В-третьих, неэффективность налоговых реформ. В течение последних 15 лет в России проводится масштабная налоговая реформа, однако до сих пор отечественная налоговая система остается громоздкой и мало экономичной. Применяемые методы администрирования собираемых платежей также не были эффективными. Как следствие, в России массовое уклонение от налогов приобрело угрожающий характер, неуплата налогов в общественном сознании на протяжении последнего десятилетия не воспринималась как обязанность законного гражданина, а схемы уклонения от налогов с каждым годом становятся все изощреннее.

В-четвертых, избыточное или неэффективное администрирование, низкое качество предоставляемых государственных услуг, что может повлечь ограничение развития предпринимательства, «бегство» участников в другие юрисдикции, серую и черную зоны бизнеса, которые не поддаются никакому налоговому администрированию. В результате отсутствие развития экономики, возрастание социальной напряженности, нагрузки на бюджет, коррупционных факторов. Низкая собираемость налогов и рост выявляемых в ходе налоговых проверок сумм неуплаченных обязательных платежей привели к активизации борьбы с налоговыми правонарушениями и ужесточению налогового контроля [6, с.151].

$$
\text { В-пятых, несовершенство и }
$$

неэффективность налогового администрирования. Позитивных сдвигов в налоговой сфере без системных и комплексных изменений пока не наблюдается. Спешно вводимые формы налогового администрирования не обеспечивают ожидаемые показатели эффективности. В настоящее время половина общих сборов НДС уходит на возвраты. 
Поступления налога на прибыль не дают прироста. Применение «плоской» шкалы подоходного налога с физических лиц не обеспечило легализацию зарплат и отказ от выплаты заработной платы «в конвертах». Если рассматривать распределение предпринимательской активности субъектов малого бизнеса по отраслям, то одной из основных сфер малого бизнеса является организация общественного питания - сфера бизнеса крайне сложная для проведения углубленного налогового контроля.

Для решения выше обозначенных проблем нами предлагаются следующие пути развития налогового администрирования.

Проанализировав тенденции реформ налогового администрирования предприятий малого и среднего бизнеса, предлагается продолжить меры по ужесточению методов и приемов налогового контроля. На данном этапе ужесточение налогового администрирования дает свои результаты. За первый квартал 2017 года по сравнению с тем же периодом 2016 года показатель собираемости платежей в бюджеты всех уровней обозначил положительную динамику. В качестве основного инструмента налогового администрирования, в первую очередь, использовать налоговый контроль.

Для решения проблемы наполняемости бюджета в практику налогового администрирования в субъектах федерации внедрить информационные технологии, позволяющие отслеживать и выявлять незаконные действия налогоплательщиков. Широкое применение информационных технологий в сфере государственного управления, в том числе в налоговой области. Расширять возможности электронного взаимодействия с налогоплательщиками и государственными и муниципальными органами власти и иными организациями за счет внедрения электронных услуг и сервисов, что позволит обеспечить наполняемость бюджетов всех уровней бюджетной системы.

Усилить контроль за переходом к началу 2018 года предприятий малого и среднего бизнеса на электронную контрольно-кассовую технику нового поколения, отправляющую информацию о продаже напрямую в инспекции. Это позволит проверяющим налоговых органов иметь доступ к полной информации, в каком регионе, какие суммы и сколько коммерсантов получают доход, а также будет способствовать наполняемости бюджета и легализации отечественного бизнеса.

Обеспечить внедрение электронных систем, направленных на легализацию «серого бизнеса», позволяющих контролировать и предотвращать утечку денежных средств в теневой бизнес.
Самые значимым примером является система «Платон», которая подразумевает взимания налога с большегрузных автомобилей за передвижения по федеральным трассам. Другой пример, внедрение системы ЕГАИС обеспечивающая государственный контроль в алкогольной отрасли. Обе системы в значительной степени затратны для малого бизнеса, но обе обеспечивают легализацию ранее скрываемых объемов продаж.

Продолжить наращивать и дорабатывать автоматизацию контроля налогов, включая в нее все региональные инспекции, изменяя подходы к работе с налогоплательщиками. Прежде всего клиентоориентированность, упрощение способов взаимодействия с налоговыми органами, создание более комфортных условий для исполнения налогоплательщиками своих обязанностей [1, с.24]. В связи с рассмотрением возможностей использования новых информационных технологий в налоговом администрировании следует отметить: развитие и улучшение электронных сервисов, связанных с регистрацией налогоплательщиков и представлением налоговой отчетности в электронном виде; создание специализированных информационных ресурсов для налогоплательщиков; развитие средств контроля и мониторинга, а также развитие средств электронного дистанционного консультирования.

Обеспечить проведение агрессивной рекламы для полного использования информационного ресурса «Личный кабинет» налогоплательщика. Данный ресурс позволяет налогоплательщикам получать от налогового органа документы, передавать в налоговый орган информацию, сведений в электронной форме, осуществлять контроль за состоянием расчетов с бюджетом по налогам, обращаться в налоговые органы без личного визита, а также самостоятельно формировать платежные документы, оплачивать суммы недоимки и налоговые платежи.

Совершенствовать систему «АИС Налог», которая позволяет контролирующим органам дистанционно, без лишних запросов в другие налоговые органы, мониторить администрирование налога на добавленную стоимость, а также обеспечивает взаимосвязь проверяемого лица с контрагентами, анализировать книгу покупок и книгу продаж данного налогоплательщика, составлять «дерево связи» той или иной сделки.

Анализ, в основе которого лежат гибкие информационные системы, может помочь исполнительным органам власти принимать решения объективнее, т.к. в данном случае налоговое администрирование основывается на обширном статистическом материале. Плюсы 
использования

информационных систем очевидны: появляется возможность смоделировать различные ситуации в лабораторных условиях, а затем применить их на практике. Закономерно встает вопрос о качестве собранной информации и методах ее формирования. Здесь практики исходят из жизненных реалий налогового администрирования. Фактические значения налоговых поступлений и начислений зависят от эффективности налогового контроля, способности органов государственной власти бороться с «черной бухгалтерией». Однако для повышения качества поступающей информации и, как следствие, увеличения финансовых ресурсов, поступающих в бюджет, могут быть предложены дополнительные механизмы автоматизации контроля.

Повышение открытости налоговых органов, автоматизация бизнес-процессов и комплексное использование накопленной в ФНС России информации способны перевести работу налоговых инспекций в область «налогового автомата», когда вся налоговая информация по четко заданным алгоритмам будет обрабатываться в автоматическом режиме [5 c.30].

\section{Conclusion}

Полагаем, что реализация предложенных мероприятий по совершенствованию налогового администрирования предприятий малого и среднего бизнеса обеспечит рост собираемости налогов и наполняемость бюджетов всех уровней. Позволит налоговым органам перейти от административно-командной модели налогового администрирования, основанной на односторонне-властном управленческом воздействии с приоритетом контрольнопринудительных средств, к модели «партнерского сотрудничества», в основе которой лежит принцип «клиентоориентированного сервиса», досудебного разрешения споров, взаимного доверия и взаимовыгодного «обмена» управляемых с управляемыми. Контролирующие органы обеспечат максимально прозрачную систему взаиморасчетов компаний, повышая вероятность значительного увеличения организаций, которые выйдут из тени. Высокотехнологичная автоматизация бизнеспроцессов упрощает налогоплательщику ведение бизнеса и позволяет налоговым органам обеспечить автоматизированный своевременный и эффективный контроль. В целом это позволит улучшить условия исполнения налогоплательщиками своих обязанностей по уплате налогов и сборов, а также повысить уровень налоговой дисциплины и грамотности налогоплательщиков.

\section{References:}

1. Zhuravleva O.O., Ismailova L.Yu. (2012) Novyie informatsionnyie mass-mediynyie tehnologii $\mathrm{v}$ nalogovom administrirovanii. Mirovyie trendyi i otechestvennaya praktika // Finansovoe pravo, 2012, \# 9, p. 21 - 27.

2. (2017) Rasporyazheniya Pravitelstva RF ot 02.06.2016 \# 1083-r, Strategiya razvitiya malogo i srednego predprinimatelstva V Rossiyskoy Federatsii na period do 2030 goda// [Elektronnyiy resurs]. Available: http://government.ru/media/files/jFDd9wbAbA pxgEiHNaXHveytq7hfPO96.pdf (Accessed: 10.05.2017).

3. (2017) Statisticheskie dannyie po malyim predpriyatiyam // Federalnaya sluzhba gosudarstvennoy statistiki. [Elektronnyiy resurs]. Available: http://www.gks.ru/wps/wcm/connect/rosstat_m ain/rosstat/ru/statistics/enterprise/reform/

(Accessed: 13.05.2017).

4. (2017) Tenevoy biznes $\mathrm{V}$ tsifrah // [Elektronnyiy resurs]. Available: http://alterainvest.ru/news/article-334974/ (Accessed: 13.05.2017).

5. Efremova T.A. (2017) Povyishenie effektivnosti nalogovogo administrirovaniya kak neobhodimoe uslovie razvitiya nalogovoy sistemyi // Nalogi, 2017, \# 2, p. 27 - 31.

6. Boboshko N.M. (2015) Analiz problem dinamiki razvitiya nalogovoy sistemyi Rossii // Vestnik ekonomicheskoy bezopasnosti, 2015, \# 7. p. 147 - 152.

7. Efremova T.A., Efremova L.I. (2010) Avtomatizatsiya nalogovoy deyatelnosti // Aktualnyie voprosyi ekonomicheskih nauk. 2010. \# 11 - 3. p. 29 - 34. 
\begin{tabular}{l|lrl|l|ll} 
& ISRA (India) & $=\mathbf{1 . 3 4 4}$ & SIS (USA) & $=\mathbf{0 . 9 1 2}$ & ICV (Poland) & $=\mathbf{6 . 6 3 0}$ \\
Impact Factor: & ISI (Dubai, UAE) $=\mathbf{0 . 8 2 9}$ & PUHL (Russia) $=\mathbf{0 . 2 0 7}$ & PIF (India) & $=\mathbf{1 . 9 4 0}$ \\
& GIF (Australia) & $\mathbf{0 . 5 6 4}$ & ESJI (KZ) & $=3.860$ & IBI (India) & $=\mathbf{4 . 2 6 0}$ \\
& JIF & $\mathbf{1 . 5 0 0}$ & SJIF (Morocco) & $=\mathbf{2 . 0 3 1}$ & & \\
\hline
\end{tabular}

8. (2017) Dannyie po formam statisticheskoy nalogovoy otchYotnosti/Otchet o zadolzhennosti po nalogam i sboram, penyam i nalogovyim sanktsiyam $\mathrm{V}$ byudzhetnuyu sistemu Rossiyskoy Federatsii " za 2015 god (forme 4-NM za2014g., 2015g.,2016g.) //FNS Rossii [Elektronnyiy resurs]. Available: https://www.nalog.ru/rn14/related_activities/sta tistics_and_analytics/forms/5248246/

(Accessed: 10.05.2017).

9. (2017) Dannyie po formam statisticheskoy nalogovoy otchYotnosti/Otchet o nachislenii $\mathrm{i}$ postuplenii nalogov, sborov i inyih obyazatelnyih platezhey $\mathrm{v}$ byudzhetnuyu sistemu Rossiyskoy Federatsii po forme \#1NM//FNS Rossii [Elektronnyiy resurs]. Available:

https://www.nalog.ru/rn14/related_activities/sta tistics and analytics/forms/ (Accessed: 11.05.2017).

10. Strelnikova K.O. (2016) Povyishenie nalogovoy gramotnosti naseleniya kak instrument uluchsheniya nalogovogo administrirovaniya // Sovremennyie problemyi vzaimodeystviya rossiyskogo gosudarstva i obschestva: Sbornik statey. M., 2016. p. 91 - 94. 